\title{
Risk assessment of Diabetes using the Indian Diabetes Risk Score in an urban resettlement colony of East Delhi
}

\author{
Anita S. Acharya ${ }^{1}$, Shibajee Debbarma ${ }^{2}$, Sanjeev Kumar Rasania ${ }^{3}$, Nidhi Tiwari $^{4}$, Damodar Bachani ${ }^{5}$, Jyoti \\ Khandekar ${ }^{6}$
}

${ }^{1}$ Professor, Department of Community Medicine, Lady Hardinge Medical College, New Delhi; ${ }^{2}$ Senior Resident, Department of Community Medicine, Lady Hardinge Medical College, New Delhi; ${ }^{3}$ Director Professor \& Head, Department of Community Medicine, Lady Hardinge Medical College, New Delhi; ${ }^{4}$ Consultant, HMIS, Ministry of Health \& Family Welfare; ${ }^{5}$ Deputy Project Director, "Building Healthy Cities", John Snow India Pvt. Ltd., New Delhi; ${ }^{6}$ Director Professor, Department of Community Medicine, Lady Hardinge Medical College, New Delhi

\begin{tabular}{|c|c|c|c|c|c|c|c|c|}
\hline Abstract & Introduction & Methodology & Results & Conclusion & References & Citation & \multicolumn{2}{|c|}{ Tables / Figures } \\
\hline \multicolumn{9}{|c|}{ ing $A$} \\
\hline \multicolumn{8}{|c|}{$\begin{array}{l}\text { Dr Shibajee Debbarma, Department of Community Medicine, Lady Hardinge Medical College, New Delhi- } \\
110001 \\
\text { E Mail ID: darth.24@gmail.com }\end{array}$} & 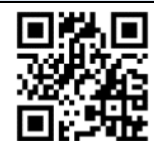 \\
\hline
\end{tabular}

\section{Citation}

Acharya AS, Debbarma S, Rasania SK, Tiwari N, Bachani D, Khandekar J. Risk assessment of Diabetes using the Indian Diabetes Risk Score in an urban resettlement colony of East Delhi. Indian J Comm Health. 2020;32(2):354-358.

Source of Funding: Financially supported by the Indian Council of Medical Research, Task force grant No. 5/7/1/208RHN, IRIS number 2008-0826, A to C Conflict of Interest: None declared

\section{Article Cycle}

Received: 31/03/2020; Revision: 15/04/2020; Accepted: 20/06/2020; Published: 30/06/2020

This work is licensed under a Creative Commons Attribution 4.0 International License.

\section{Abstract}

Background- The burden of diabetes in India is expected to worsen in the coming years. Indian Diabetes Risk Score (IDRS) is a validated and cost-effective tool to identify risk of developing diabetes among population. Objectives- To assess the risk of Type 2 Diabetes mellitus using the IDRS in adults aged 30 years and above and to study the association of risk of diabetes with other factors. Material \& Methods- A cross-sectional study was conducted in Kalyanpuri area of East Delhi. Data collection was done from August to December, 2018. 494 residents aged 30 years and above were included in the study. Data was collected using a semi-structured questionnaire. SPSS version 23 was used for data analysis. Results- $43.7 \%$ of the study subjects were aged 50 years or above and majority (65.38\%) were females. More than half $(59.31 \%)$ of the subjects were found to have high risk of diabetes. Age and central obesity were found to be significantly associated with risk of diabetes $(p<0.05)$. Risk of developing diabetes was not associated with gender. Conclusion- Early detection of risk of diabetes by periodic screening and appropriate behavioral change communication would be effective in controlling the diabetes crisis.

\section{Keywords}

Diabetes, Indian Diabetes Risk Score, Waist circumference, Physical activity

\section{Introduction}

Diabetes has emerged as a global pandemic of the 21st century. Approximately 463 million adults (20-79 years) were living with diabetes worldwide in 2019. (1) Of the different types, Type 2 Diabetes mellitus (T2DM) is the most common. (1) Considered to be a disease of the developed countries earlier, it is now more prevalent in developing countries. Various factors are responsible for this change in prevalence and pattern of spread. The workforce in developing countries has shifted to less physically demanding occupations following industrialization and mechanization. Over the years, there has also been changes in dietary patterns of the population with more inclination towards unhealthy diet which along with family history and other factors contribute to this increasing prevalence.

India has the second largest number of adults living with diabetes worldwide (77 million). (1) The burden of diabetes in India is expected to worsen in the coming years. Almost half of the diabetics in India are unaware of their disease status. (2) There is need for mass awareness and screening programs to identify and overcome the disease burden. The present study was planned to identify subjects who are at risk of developing diabetes using the Indian Diabetes Risk Score (IDRS). 


\section{Aims \& Objectives}

1. To assess the risk of Type 2 Diabetes mellitus using the IDRS in adults aged 30 years and above.

2. To study association of risk of diabetes with various factors.

\section{Material \& Methods}

Study type- Community-based, cross-sectional study. Study Population- Residents of blocks 12 and 18 of Kalyanpuri.

Study Area- Kalyanpuri area of East Delhi is an urban resettlement colony and is one of the field practice areas of Department of Community Medicine of one of the premier medical college of New Delhi.

Study Duration- Data collection was done from August to December, 2018.

Sample Size calculation- Kalyanpuri has eleven blocks numbering 11 to 21 . Out of these, blocks 12 and 18, were randomly selected. Four hundred and ninety-four residents of the two blocks were included in the study. Inclusion criteria-

1. Residents aged 30 years and above.

2. Those who gave consent for the study.

Exclusion criteria-

1. Those who were previously diagnosed as diabetic.

2. Those who were pregnant.

Strategy for collection- Data was collected using a semistructured questionnaire. Anthropometric measurements were done using standard methods and recorded.

Working definition- The Indian Diabetes Risk Score (IDRS) is a validated tool to identify individuals with high risk of developing type 2 diabetes mellitus (T2DM). (3) It considers four risk factors namely age, waist circumference, physical activity and family history of diabetes. The study participants were classified into Low risk (<30), Moderate risk (30-50) and High risk (=>60) based on the scores obtained.

\begin{tabular}{|c|c|}
\hline & Score \\
\hline \multicolumn{2}{|l|}{ Age } \\
\hline$<35$ years & 0 \\
\hline $35-49$ years & 20 \\
\hline$=>50$ years & 30 \\
\hline \multicolumn{2}{|l|}{ Waist circumference } \\
\hline $\begin{array}{l}\text { Waist }<80 \mathrm{~cm} \text { (female), }<90 \mathrm{~cm} \\
\text { (male) }\end{array}$ & 0 \\
\hline $\begin{array}{l}\text { Waist }=>80-89 \mathrm{~cm} \text { (female), =>90-99 } \\
\mathrm{cm} \text { (male) }\end{array}$ & 10 \\
\hline $\begin{array}{l}\text { Waist }=>90 \mathrm{~cm} \text { (female), =>100 cm } \\
\text { (male) }\end{array}$ & 20 \\
\hline \multicolumn{2}{|l|}{ Physical activity } \\
\hline $\begin{array}{l}\text { Regular vigorous exercise or } \\
\text { strenuous (manual) activities at } \\
\text { home/work }\end{array}$ & 0 \\
\hline
\end{tabular}

\begin{tabular}{|l|r|}
\hline $\begin{array}{l}\text { Regular moderate exercise or } \\
\text { moderate physical activity at } \\
\text { home/work }\end{array}$ & 10 \\
\hline $\begin{array}{l}\text { Regular mild exercise or mild } \\
\text { physical activity at home/work }\end{array}$ & 20 \\
\hline $\begin{array}{l}\text { No exercise and/or sedentary } \\
\text { activities at home/work }\end{array}$ & 30 \\
\hline $\begin{array}{l}\text { Family history of diabetes } \\
\text { No diabetes in parents }\end{array}$ & 0 \\
\hline One parent is diabetic & 10 \\
\hline Both parents are diabetic & 20 \\
\hline
\end{tabular}

Ethical Approval- This study was part of an Indian Council of Medical Research (ICMR) task force project titled "Health Accounting Scheme". Institutional Ethical Committee clearance was obtained.

Consent- A written consent was obtained from the study participants.

Data Analysis- Statistical Package for Social Sciences (SPSS) version 23 was used for data analysis and $p<0.05$ was considered as statistically significant.

\section{Results}

Out of 494 study subjects, $43.7 \%$ were aged 50 years or above (Table 1 ). Majority (65.38\%) of the study subjects were females. Among those who were illiterate (32.19\%), majority (86.16\%) were females. Most $(57.29 \%)$ of the study subjects were housewives. Most of the males (56.14\%) as well as females (60.99\%) were having high IDRS values (Table 2). Waist circumference of half $(52.05 \%)$ of the male subjects was $=>90-99 \mathrm{~cm}$ while most $(60.68 \%)$ of the females had waist circumference $=>90 \mathrm{~cm}$ (Table 3). Majority (82.39\%) of the subjects said that they regularly did mild exercise or physical activity at home or work while $15.79 \%$ did no exercise or had sedentary activity. There was no family history of diabetes in majority of the subjects (82.39\%). Increasing age, larger waist circumference and sedentary lifestyle with lack of physical activity were found to be significantly associated with risk of diabetes $(p<0.05)$ (Table 4$)$. Majority $(75 \%)$ of the subjects with family history of diabetes of both parents were found to have high risk score. Risk of developing diabetes was not significantly associated with gender ( $p>0.05)$.

\section{Discussion}

In our study, $43.7 \%$ of the subjects were aged 50 years and above followed by those between $35-49$ years age (38.9\%) and the rest were between $30-<35$ years of age. The agewise distribution varied according to the availability of subjects at the time of the study. Most $(65.38 \%)$ of the study subjects were females which is similar to other studies conducted in India. $(4,5,6,7)$ This might be due to the timings during which our study was conducted which coincided with working hours of most of the population of Kalyanpuri area. In our study, majority (67.81\%) of the subjects were literate which is similar to the finding of Chandigarh Urban Diabetes Study conducted by Walia R 
et al. (6) However, rate of illiteracy was higher among females in our study. In the present study, most (57.29\%) of the study subjects were housewives while $23.68 \%$ were unskilled, semi-skilled and skilled workers. This is similar to the finding of Garg A et al in Delhi whereby majority of study subjects were housewives followed by unskilled, semi-skilled and skilled workers. (8) In our study, majority $(82.59 \%)$ of the subjects were married which is in line with the findings of Prenissl J et al and Kumar C et al. $(2,9)$ In our study, more than half (59.31\%) of the subjects were having high IDRS values while $37.65 \%$ were with moderate risk scores. Similar findings were observed in a study conducted by Toppo NA et al in Jabalpur, Madhya Pradesh. (10) In a study conducted by Dudeja P et al also, it was found that majority of the subjects who were previously undiagnosed for diabetes, were having high IDRS values. (11) High IDRS values were seen in greater percentage of both males as well as females in our study. Waist circumference which corresponds to central obesity, is a simple, non-invasive and accurate predictor of the risk of type 2 diabetes and is better than other indices like Waist-Hip Ratio (WHR), Abdominal Volume Index (AVI), conicity index and Body Mass Index (BMI).(4,12) It has cut-off values of $85 \mathrm{~cm}$ for men and 80 $\mathrm{cm}$ for women among Asian Indian adults.(13) In the present study, central obesity was found to be highly prevalent among both male and female study subjects. Majority of the males had high waist circumference of $=>90-99 \mathrm{~cm}(52.05 \%)$ and $=>100 \mathrm{~cm}(22.22 \%)$. Similarly, majority of females had high waist circumference of $=>80$ $89 \mathrm{~cm}(25.39 \%)$ and $=>90 \mathrm{~cm}(60.68 \%)$. This finding is similar to the finding of Khan MM et al in Lucknow (U.P) where waist circumferences of majority of males and females were more than the cut-off values. (14)

In the present study, majority $(82.39 \%)$ of study participants reported to be involved in mild physical activity while the rest were involved in sedentary activity (15.79\%), strenuous activity (1.42\%) and moderate activity (0.4\%). In a study conducted in the same Kalyanpuri area by Singh A et al, majority (62.9\%) of the study subjects were moderate workers and $31.2 \%$ were sedentary workers. (15) This difference might be due to the fact that in our study, the type of physical activity was self-reported and depended on the self-perception.

Various studies have shown that genetic factor plays an important role in diabetes. $(4,16)$ However in our study, though majority $(88.87 \%)$ had no family history of diabetes, almost $97 \%$ of subjects were found to be having moderate (37.65 \%) to high (59.31\%) risk of developing diabetes as per IDRS. This is in line with the findings of Khan MM et al and Singh A et al whereby majority of study subjects did not report any family history of diabetes. $(14,15)$ This might be attributed to the unawareness of study subjects regarding previous history of diabetes in their families. However, this finding is alarming and stresses on the need of awareness generation along with appropriate dietary changes and lifestyle modification even among people with no previous family history, in view of this ever-increasing burden of diabetes.

In the present study the risk of diabetes as predicted by the IDRS, increased significantly with age $(p=0.000)$ which is similar to the findings of Dasappa et al and the Chandigarh Urban Diabetes Study. $(4,6)$ There was no significant association of gender with risk of diabetes $(p=0.298)$. Huebschmann $A G$ et al in their narrative review also concluded that association of gender alongwith various biological, environmental and behavioral mediators for T2DM needs further extensive research.(17) In our study, family history was not significantly associated with risk of diabetes $(p=0.865)$. This is similar to the finding of Dasappa et al whereby family history was not found to be significantly associated with pre-diabetes. (4) However, high IDRS values were observed among those who had at least one parent (64.7\%) or both parents (75.0\%) diabetic indicating higher chances of developing diabetes.

Majority $(85.5 \%)$ of study subjects with high waist circumference, that is, $=>100 \mathrm{~cm}$ in males and $=>90 \mathrm{~cm}$ in females, had high risk scores. Waist circumference which is an estimate of central obesity was significantly associated with increased risk of diabetes $(p=0.000)$. This is similar to the findings of various other studies done in India. $(4,12)$ In the present study, $75.6 \%$ of subjects with sedentary lifestyle had high IDRS values as compared to $56.3 \%$ subjects who were physically active and had high risk scores. Our study found that physical activity has a significant association with risk of diabetes $(p=0.003)$. This is in line with several other studies whereby physical inactivity was found to be significantly associated with diabetes and pre-diabetes. $(4,6,18)$

\section{Conclusion}

As per our study, the risk of diabetes increases with age. Majority of the study subjects were apparently healthy and were yet found to be having high risk scores. Significant association was seen between waist circumference and the risk of developing diabetes in future. Physical inactivity was also found to be significantly associated with risk of diabetes. The association of gender with risk of diabetes needs to be investigated further.

\section{Recommendation}

Rapid changes in lifestyle in India following economic growth and improvement of standards of living with an inclination towards Western culture has led to dramatic rise in the burden of Type 2 diabetes mellitus and various other non-communicable diseases. A significant issue is the unawareness of the population regarding their diabetes status. Early detection of risk of diabetes by periodic screening and appropriate behavioral change communication for adopting a healthy lifestyle might control the diabetes crisis of the country in future. 


\section{Relevance of the study}

Assessment tools like IDRS can help in rapid screening of community and can be employed on a larger scale to identify the prevalence of risk factors of diabetes in the population.

\section{Authors' Contribution}

Each author has contributed equally.

\section{Acknowledgement}

We are grateful for valuable guidance from (Late) Prof. Dr. Deoki Nandan, Dr. Soumya Swaminathan, Dr. Balram Bhargava, Dr. V. M. Katoch, Dr. R. S. Sharma and Dr. Neeta Kumar.

\section{References}

1. International Diabetes Federation. IDF Diabetes Atlas, 9th edition. Brussels; 2019

2. Prenissl J, Jaacks LM, Mohan V, Manne-Goehler J, Davies JI, Awasthi A, Bischops AC, Atun R, Bärnighausen T, Vollmer S, Geldsetzer P. Variation in health system performance for managing diabetes among states in India: a cross-sectional study of individuals aged 15 to 49 years. BMC Med. 2019 May 13;17(1):92. doi: 10.1186/s12916-019-1325-6. PubMed PMID: 31084606; PubMed Central PMCID: PMC6515628.[PubMed]

3. Mohan V, Deepa R, Deepa M, Somannavar S, Datta M. A simplified Indian Diabetes Risk Score for screening for undiagnosed diabetic subjects. J Assoc Physicians India. 2005 Sep;53:759-63. PubMed PMID: 16334618.[PubMed]

4. Dasappa H, Fathima FN, Prabhakar R, Sarin S. Prevalence of diabetes and pre-diabetes and assessments of their risk factors in urban slums of Bangalore. J Family Med Prim Care. 2015 JulSep;4(3):399-404. doi: 10.4103/2249-4863.161336. PubMed PMID: 26288781; PubMed Central PMCID: PMC4535103.[PubMed]

5. Singh MM, Mangla V, Pangtey R, Garg S. Risk Assessment of Diabetes Using the Indian Diabetes Risk Score: A Study on Young Medical Students from Northern India. Indian J Endocrinol Metab. 2019 Jan-Feb;23(1):86-90. doi: 10.4103/ijem.IJEM_623_18. PubMed PMID: 31016160; PubMed Central PMCID: PMC6446666.[PubMed]

6. Walia $R$, Bhansali $A$, Ravikiran $M$, Ravikumar $P$, Bhadada $S K$, Shanmugasundar G, Dutta $P$, Sachdeva N. High prevalence of cardiovascular risk factors in Asian Indians: a community survey Chandigarh Urban Diabetes Study (CUDS). Indian J Med Res. 2014 Feb;139(2):252-9. PubMed PMID: 24718400; PubMed Central PMCID: PMC4001337. [PubMed]

7. Thomas T, Prabhata S, Valsangkar S. Diabetes screening and the distribution of blood glucose levels in rural areas of North India. $J$ Family Community Med. 2015 Sep-Dec;22(3):140-4. doi:
10.4103/2230-8229.163026. PubMed PMID: 26392793; PubMed Central PMCID: PMC4558734.[PubMed]

8. Garg A, Anand T, Sharma U, Kishore J, Chakraborty M, Ray PC, Ingle GK. Prevalence of Risk Factors for Chronic Non-communicable Diseases Using WHO Steps Approach in an Adult Population in Delhi. J Family Med Prim Care. 2014 Apr;3(2):112-8. doi: 10.4103/2249-4863.137617. PubMed PMID: 25161966; PubMed Central PMCID: PMC4139989.[PubMed]

9. Kumar C, Dobhal P, Kashyap A. Prevalence and pattern of risk factors for non-communicable diseases in urban population of Jaipur, Rajasthan. Int J Community Med Public Health. 2019;6(7):3107-12

10. Toppo NA, Gupta V, Kasar P, Thakur A, Pandey D. Diabetes Prevalence and Its Association with IDRS among Patients' Attendees of Tertiary Care Centre of Jabalpur District of Madhya Pradesh. Int J Innov Res Med Science. 2017;2(4):644-9

11. Dudeja P, Singh G, Gadekar T, Mukherji S. Performance of Indian Diabetes Risk Score (IDRS) as screening tool for diabetes in an urban slum. Med J Armed Forces India. 2017;73(2):123-8

12. Mamtani MR, Kulkarni HR. Predictive performance of anthropometric indexes of central obesity for the risk of type 2 diabetes. Arch Med Res. 2005; 36:581-9

13. Dudeja P, Singh G, Gadekar T, Mukherji S. Performance of Indian Diabetes Risk Score (IDRS) as screening tool for diabetes in an urban slum. Med J Armed Forces India. 2017 Apr;73(2):123-128. doi: 10.1016/j.mjafi.2016.08.007. Epub 2016 Oct 18. PubMed PMID: 28924311; PubMed Central PMCID: PMC5592265.[PubMed]

14. Khan MM, Sonkar GK, Alam R, Mehrotra S, Khan MS, Kumar A Sonkar SK. Validity of Indian Diabetes Risk Score and its association with body mass index and glycosylated hemoglobin for screening of diabetes in and around areas of Lucknow. J Family Med Prim Care. 2017 Apr-Jun;6(2):366-373. doi: 10.4103/2249-4863.220010. PubMed PMID: 29302549; PubMed Central PMCID: PMC5749088. [PubMed]

15. Singh A, Acharya AS, Dhiman B. Shared risk factors of noncommunicable diseases: A community-based study among adults in an urban resettlement colony of Delhi. Indian J Community Fam Med. 2018; 4:42-8

16. Radha V, S Kanthimathi S, Mohan V. Genetics of Type 2 diabetes in Asian Indians. Diabetes Manage. 2011;1(3):309-24

17. Huebschmann AG, Huxley RR, Kohrt WM, Zeitler P, Regensteiner $J G$, Reusch JEB. Sex differences in the burden of type 2 diabetes and cardiovascular risk across the life course. Diabetologia. 2019 Oct;62(10):1761-1772. doi: 10.1007/s00125-019-4939-5. Epub 2019 Aug 27. Review. PubMed PMID: 31451872; PubMed Central PMCID: PMC7008947.[Pubmed]

18. Wilmot EG, Edwardson CL, Achana FA, Davies MJ, Gorely T, Gray LJ, Khunti K, Yates T, Biddle SJ. Sedentary time in adults and the association with diabetes, cardiovascular disease and death: systematic review and meta-analysis. Diabetologia. 2012 Nov;55(11):2895-905. PubMed PMID: 22890825.[PubMed]-

\section{Tables}

TABLE 1 SOCIO-DEMOGRAPHIC PROFILE OF STUDY SUBJECTS ( $\mathrm{N}=494$ )

\begin{tabular}{|c|c|c|c|c|}
\hline \multicolumn{2}{|r|}{ Socio-demographic profile } & \multicolumn{2}{|c|}{ Gender } & \multirow{2}{*}{$\begin{array}{c}\text { Total (\%) } \\
\mathrm{N}=494\end{array}$} \\
\hline & & $\begin{array}{c}\text { Male (\%) } \\
n=171(34.62)\end{array}$ & $\begin{array}{c}\text { Female }(\%) n=323 \\
(65.38)\end{array}$ & \\
\hline \multirow{3}{*}{$\begin{array}{l}\text { Age group } \\
\text { (in years) }\end{array}$} & $<35$ & $26(29.55)$ & $62(70.45)$ & $88(17.81)$ \\
\hline & $35-49$ & $60(31.58)$ & $130(68.42)$ & $190(38.46)$ \\
\hline & $=>50$ & $85(39.35)$ & $131(60.69)$ & $216(43.72)$ \\
\hline \multirow[t]{3}{*}{ Education } & Illiterate & $22(13.84)$ & $137(86.16)$ & 159 (32.19) \\
\hline & Up to High school & $98(42.24)$ & $134(57.76)$ & $232(46.96)$ \\
\hline & Above High school & $51(49.51)$ & $52(50.49)$ & $103(20.85)$ \\
\hline \multirow[t]{2}{*}{ Occupation } & Housewife & - & $283(100)$ & $283(57.29)$ \\
\hline & Unskilled/Semi-skilled/Skilled & $99(84.62)$ & $18(15.38)$ & $117(23.68)$ \\
\hline
\end{tabular}


INDIAN JOURNAL OF COMMUNITY HEALTH / VOL 32 / ISSUE NO 02 / APR - JUN 2020

[Risk assessment of]... | Acharya AS et al

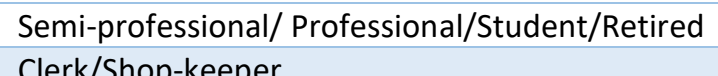

\begin{tabular}{|r|}
\hline $31(86.11)$ \\
\hline $25(86.21)$ \\
\hline $16(55.17)$ \\
\hline $151(37.01)$ \\
\hline $7(46.67)$ \\
\hline $13(18.31)$ \\
\hline
\end{tabular}

\begin{tabular}{|r|r|}
\hline Risk assessment of]... & Acharya AS et al \\
\hline $5(13.89)$ & $36(7.29)$ \\
\hline $4(13.79)$ & $29(5.87)$ \\
\hline $13(44.83)$ & $29(5.87)$ \\
\hline $257(62.99)$ & $408(82.59)$ \\
\hline $8(53.33)$ & $15(3.04)$ \\
\hline $58(81.69)$ & $71(14.37)$ \\
\hline
\end{tabular}

\begin{tabular}{|c|c|c|c|c|}
\hline \multirow{3}{*}{$\begin{array}{l}\text { Marital } \\
\text { status }\end{array}$} & Married & 151 (37.01) & 257 (62.99) & 408 (82.59) \\
\hline & Unmarried & 7 (46.67) & $8(53.33)$ & 15 (3.04) \\
\hline & Others & $13(18.31)$ & 58 (81.69) & 71 (14.37) \\
\hline
\end{tabular}

TABLE 2 RISK OF DIABETES AMONG STUDY SUBJECTS AS PER RISK SCORE (N=494)

\begin{tabular}{|l|r|r|r|r|}
\hline & & Risk of Diabetes (as per IDRS) & \multicolumn{1}{c|}{ Total } \\
\hline Male & Low Risk (<30) No. (\%) & Moderate Risk (30-50) No. (\%) & High Risk (=>60) No. (\%) & No. (\%) \\
\hline Female & $6(3.51)$ & $69(40.35)$ & $96(56.14)$ & $171(100)$ \\
\hline Total & $11(3.41)$ & $115(35.60)$ & $197(60.99)$ & $323(100)$ \\
\hline
\end{tabular}

TABLE 3 IDRS COMPONENTS OF STUDY SUBJECTS $(\mathrm{N}=494$ )

\begin{tabular}{|c|c|c|}
\hline IDRS component & Number of Subjects & Percentage (\%) \\
\hline \multicolumn{3}{|l|}{ Waist circumference } \\
\hline$<80 \mathrm{~cm}$ (Female) & 45 & 13.93 \\
\hline$<90 \mathrm{~cm}$ (Male) & 44 & 25.73 \\
\hline$=>80-89 \mathrm{~cm}$ (Female) & 82 & 25.39 \\
\hline$=>90-99 \mathrm{~cm}$ (Male) & 89 & 52.05 \\
\hline$=>90 \mathrm{~cm}$ (Female) & 196 & 60.68 \\
\hline$=>100 \mathrm{~cm}$ (Male) & 38 & 22.22 \\
\hline \multicolumn{3}{|l|}{ Physical activity } \\
\hline Regular vigorous exercise/strenuous physical activity at home or work & 07 & 1.42 \\
\hline Regular moderate exercise/moderate physical activity at home or work & 02 & 0.4 \\
\hline Regular mild exercise/mild physical activity at home or work & 407 & 82.39 \\
\hline No exercise/sedentary activity at home or at work & 78 & 15.79 \\
\hline \multicolumn{3}{|l|}{ Family history } \\
\hline No parent diabetic & 439 & 88.87 \\
\hline One parent diabetic & 51 & 10.32 \\
\hline Both parents' diabetic & 4 & 0.81 \\
\hline
\end{tabular}

TABLE 4 ASSOCIATION OF STUDY SUBJECTS CHARACTERISTICS \& RISK OF DIABETES AS PER IDRS (N=494)

\begin{tabular}{|c|c|c|c|c|}
\hline \multirow[t]{2}{*}{ Characteristics of Subjects } & \multicolumn{3}{|c|}{ Risk of Diabetes as per IDRS } & \multirow{2}{*}{$\begin{array}{l}\text { Chi-square } \\
\text { value ( } p \text { value) }\end{array}$} \\
\hline & Low risk (\%) & Moderate risk (\%) & High risk (\%) & \\
\hline \multicolumn{5}{|l|}{ Age (in years) } \\
\hline$<35$ & $13(14.8)$ & $73(83.0)$ & $2(2.3)$ & \multirow[t]{3}{*}{$217.85(0.000)$} \\
\hline $35-49$ & $0(0.0)$ & $88(46.3)$ & $102(53.7)$ & \\
\hline$\Rightarrow>50$ & $2(0.9)$ & $25(11.6)$ & $189(87.5)$ & \\
\hline \multicolumn{5}{|l|}{ Gender } \\
\hline Male & $4(2.3)$ & $72(42.1)$ & $95(55.6)$ & \multirow[t]{2}{*}{$2.42(0.298)$} \\
\hline Female & $11(3.4)$ & $114(35.3)$ & $198(61.3)$ & \\
\hline \multicolumn{5}{|l|}{ Family history of Diabetes } \\
\hline No parent & $14(3.2)$ & $168(38.3)$ & $257(58.5)$ & \multirow[t]{3}{*}{$1.277(0.865$} \\
\hline One parent & $1(2.0)$ & $17(33.3)$ & $33(64.7)$ & \\
\hline Both parents & $0(0.0)$ & $1(25.0)$ & $3(75.0)$ & \\
\hline \multicolumn{5}{|l|}{ Waist circumference } \\
\hline$\Rightarrow>100 \mathrm{~cm}$ (Male), $=>90 \mathrm{~cm}$ (Female) & $0(0.0)$ & $34(14.5)$ & $200(85.5)$ & \multirow[t]{3}{*}{$193.51(0.000)$} \\
\hline$=>90-99 \mathrm{~cm}$ (Male), =>80-89cm (Female) & $1(0.6)$ & $87(50.9)$ & $83(48.5)$ & \\
\hline$<90 \mathrm{~cm}$ (Male), $<80 \mathrm{~cm}$ (Female) & $14(15.7)$ & $65(73.0)$ & $10(11.2)$ & \\
\hline \multicolumn{5}{|l|}{ Physical activity } \\
\hline Active & $15(3.6)$ & $167(40.1)$ & $234(56.3)$ & \multirow[t]{2}{*}{$11.323(0.003)$} \\
\hline Sedentary & $0(0.0)$ & $19(24.4)$ & $59(75.6)$ & \\
\hline
\end{tabular}

